\title{
What Have We Learned about the Employment Effects of Severance Pay? Further Iterations of Lazear et al. ${ }^{\star}$
}

\author{
JOHN T. ADDISON $\star \star$ \\ Department of Economics, University of South Carolina, Columbia, USA, \\ $I Z A$, Bonn, Germany, and GEMF, Coimbra, Portugal \\ PAULINO TEIXEIRA \\ Faculdade de Economia, Universidade de Coimbra and GEMF, Coimbra, Portugal
}

\begin{abstract}
In this study we examine the effect of severance pay on employment and unemployment, using data on industrialized OECD countries. Our starting point is Lazear's [(1990) Quarterly Journal of Economics 105, 699-726] dictum that severance payment requirements unfavorably impact the labor market. We extend his sample period and add to his parsimonious specification a variety of fixed and time-varying labor market institutions. While the positive effect of severance pay on unemployment garners some support, there is no real indication of adverse effects in respect of the other employment outcomes identified here, namely, the employment-population ratio, the labor force participation rate, and long-term unemployment. Moreover, with the possible exception of collective bargaining coordination, the role of institutions is also more muted than suggested in the literature.
\end{abstract}

Key words: Severance pay, employment protection, employment, unemployment, labor force participation, time-varying labor market institutions

JEL codes: J23, J64, J65

\section{Introduction}

Refocused by the work of Lazear (1990), analysis of the impact of job security provisions on labor market outcomes was among the most studied topics in labor economics during the decade of the 1990s and, now extending beyond proximate causation, shows every sign of continuing to be a key research theme in the first decade of the new millennium (see, in particular,

$\star$ We thank, without implicating, an anonymous referee for most helpful comments on the first draft of this paper.

$\star \star$ Author for correspondence. John T. Addison, Department of Economics, University of South Carolina, 1705 College Street, Columbia, SC 29208, USA. Phone: + 1-803-777-4608; Fax: + 1-803-777-6876; E-mail: ecceaddi@moore.sc.edu 
Botero et al., 2004). ${ }^{1}$ Interest in employment protection remains keen because of continuing high unemployment and sluggish growth in much of Europe. However, the economics profession has failed to provide consistent results on the consequences of employment protection, as is evidenced by the very pessimistic conclusions of, say, Heckman and Pagés (2000) on the one hand and the guarded optimism of the OECD (1999) on the other.

Although theory can provide the basis for different expectations regarding the effects of employment protection on labor market outcomes, data limitations would seem in this case to have played a more important role than usual in accounting for diversity of finding (on which, see Addison and Teixeira, 2003). The data problems are reflected in models that are parsimonious in both the range of explanatory variables deployed and in the time frame examined. To be sure, in the years following Lazear's pioneering analysis the data situation has improved in terms of refinements to the key independent variable and with the availability of information on new regressors. Nevertheless, data constraints have continued to cast a long shadow over the economic analysis of employment protection. In particular, the needs of wider country coverage and an extended time series have consequences for the number of explanatory variables than can be included in the empirical model. The tradeoffs that have to be made ought to have inculcated more humility on the part of investigators than is apparent in the literature.

The purpose of the present paper is twofold. First, we seek to document the problems arising from the prototypical parsimonious model, using Lazear's famous paper as an organizing device. In updating Addison et al. (2000), we will further discuss the robustness of Lazear's major findings on the effects of his preferred measure of job security - namely, the no-fault severance pay granted to a blue-collar worker with 10 years service, or SEV on employment and unemployment rates. Our sample covers an (extended) interval of more than four decades, namely, from 1956 to 1999. In a new departure, we will also address the course of long-term unemployment - and drop the average weekly hours worked by production workers measure used by Lazear ${ }^{2}$ - albeit for a shorter sample period (1979-1999).

Our second goal is to determine whether the use of more comprehensive measures of job protection (such as the OECD composite index of the severity or coerciveness of employment laws, given in Table I below) and the incorporation of other labor market institutions lead to different labor market outcomes than suggested by the SEV regressor alone. Replacement of the partial indicator SEV by some composite index capturing other seemingly important aspects of the job regulatory framework - such as a measure of procedural delays in dismissals and the permissibility of fixed-term contracts - is expected to improve the explanatory power of the model, although this advantage might be compromised by a shortened time series. Similarly, the 
failure to model (the degree of) collective bargaining coverage or (the extent of) employee and employer coordination in wage bargaining might be no less serious a source of bias in the estimated parameters than the use of a partial indicator of employment protection.

As a practical matter, most measures of 'labor market institutions' are seldom available in a continuous form. They are either one-off, purpose-built constructs or observed only at a few points in time. ${ }^{3}$ This reality leaves the researcher with two options: either assume these variables have effects that are roughly constant over time and run the model on fixed institutions (in which case the analysis can be extended to cover almost half a century), or instead assume time-varying institutions and trade a presumably more informative set of institutions off against a substantially smaller number of observations (through the reduction in the respective time series). To evaluate the sensitivity of the parsimonious specification used by Lazear, therefore, we shall follow two routes. First, we use annual data in conjunction with fixed institutions throughout (i.e. from 1956 up to 1999). Second, and this is our preferred route, we average our annual data on (four) labor market performance indicators over 5-year periods and use time-varying institutions for which we have observations at different moments in time (at least three). The sample period in this case is necessarily shorter and covers the period 19701999 (1979-1999 in the case of the long-term unemployment equation).

Assuming fixed labor market institutions over a period of almost half a century - the first route - seems at first glance rather heroic, but this particular pooling of cross-section and time-series data offers an indication of the effect of time-varying severance pay over an extended period that is embedded within in a richer institutional context. The second route (i.e. dropping the assumption of fixed institutions) reduces both the sample period and the number of institutions, but at least eliminates the need for interpolation in order to obtain (artificial) annual time-varying data. This approach, which also allows the researcher to focus on the long-term impact of policy intervention in labor markets, has found some favor in the literature (see Nickell, 1997; Blanchard and Wolfers, 2000; Bertola et al., 2001). Observe that our set of time-varying labor institutions and range of labor market performance indicators is wider than has been used in this literature.

\section{Modeling and Data}

\section{SPECIFICATION}

The sample panel structure of our database allows for a wide range of sensitivity tests. In the most favorable case, we will be able to work with data on 20 OECD countries over 44 consecutive years. ${ }^{4}$

We will begin with the standard Lazear specification containing country specific effects, which can be written: 


$$
y_{i t}=c_{i}+\sum_{j} X_{i j t} b_{j}+e_{i t},
$$

where $y$ denotes the particular labor market outcome, $X$ is the set of explanatory and control variables, and $c$ captures the country specific effect. The outcome indicators are fourfold: the employment-population ratio, the unemployment rate, the long-term unemployment rate, and the labor force participation rate. In Lazear's full model the vector $X$ included in addition to severance pay and a quadratic in time, a demographic control (the share of the population aged between 25 and 65 years), and the growth in GDP per capita (to accommodate the notion that a growing economy vitiates at least in part the probabilistic costs of severance pay rules). At this stage, the model assumes away any reverse causation or endogeneity of the explanatory variables although Lazear (1990, pp. 722-723) subsequently addresses the causality issue by, among other things, regressing changes in severance pay between $t$ and $t+1$ on levels at time $t$ of three of the four dependent variables. In our fitted regressions we will only address directly the problems arising from autocorrelation, where our first-pass solution will be to assume a (common) first-order serially correlated error term. Specifically, this approach will be applied in generating Tables II-IV, below, which cover the sample period 1956-99. ${ }^{5}$

Extending the vector $X$ of explanatory variables in Equation (1) to include measures of labor market institutions requires a slight change to the model specification and estimation procedures. In particular, since the inclusion of the additional regressors reduces substantially the length of the panel especially if the model includes time-varying variables - GLS random effects estimates will be used rather than the standard fixed effects model. Within this framework we will also introduce time dummies to proxy unobserved cross-country (common) shocks. This approach will be followed in Tables VVII, below, and the general formulation can be described as:

$$
y_{i t}=c_{i}+d_{t}+\sum_{j} X_{i j t} b_{j}+e_{i t},
$$

where $t$ denotes the 5-year periods, $d_{t}$ is the time effect for period $t$, and $X$ now contains the institutional variables.

Our final model extension includes the interaction of labor market institutions and time (i.e. unobserved shocks). The interaction terms are intended to capture the 'product' of shocks and institutions, the presumption being that a particularly unfavorable labor market regulation will impact labor market performance more severely in bad times. In this case, we use a nonlinear specification of the following type:

$$
y_{i t}=c_{i}+d_{t}\left(1+\sum_{j} X_{i j t} b_{j}\right)+e_{i t} .
$$




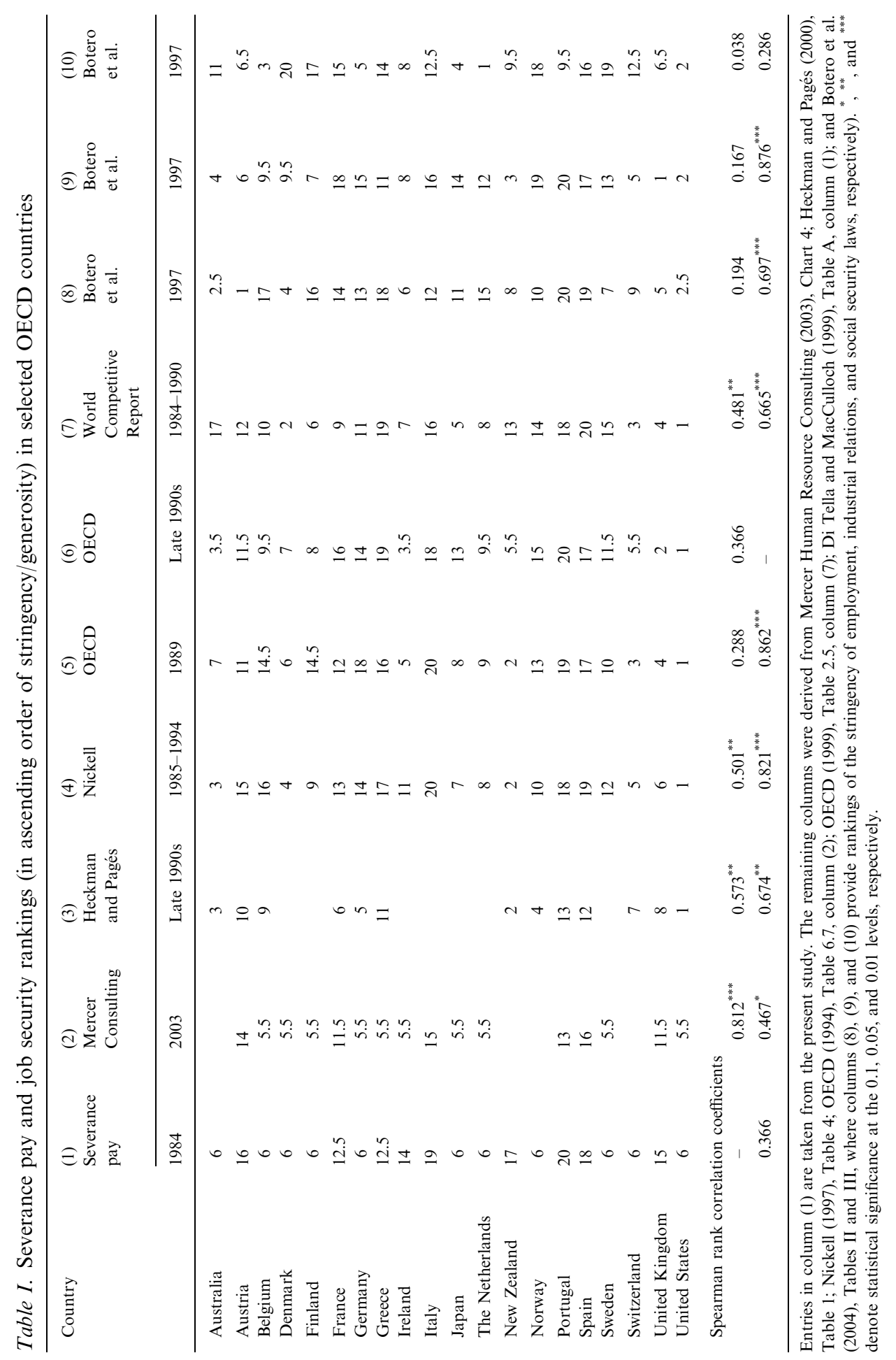


Our findings using this specification are contained in Table IX, with all variables being expressed in terms of deviations from the sample mean. ${ }^{6}$

\section{DATA}

Our database contains observations on a maximum of 20 OECD countries Austria, Australia, Belgium, Denmark, Finland, France, Germany, Greece, Ireland, Italy, Japan, the Netherlands, New Zealand, Norway, Portugal, Spain, Sweden, Switzerland, the United Kingdom, and the United States plus Israel. Information on the country sample, labor market outcomes, and explanatory variables for the base period 1956-84 is provided in Addison et al. (2000). For present purposes, we limit our comments to how we updated this information between 1985 and 1999.

Information on the employment-population ratio (EMPPOP), the unemployment rate (UNRATE), and the labor force participation rate (LFPR) was updated using the OECD publication Labor Market Statistics. This source was also used to provide information on the remaining dependent variable used in the present treatment, namely, the long-term unemployment rate (LTUNRATE). It will be recalled that LTUNRATE, information on which was only available from 1979 onward, replaces Lazear's working hours variable.

We also updated the severance payment variable (i.e. the statutory entitlement in months of pay due to a blue-collar worker with 10 years of service at termination, separated for reasons unconnected with his/her behavior), using the detailed information on dismissals procedures for 1992-1999 contained in Bertola et al. (1999). But this material covers only 11 OECD countries - Australia, Austria, Denmark, France, Germany, Ireland, Italy, New Zealand, Spain, the United Kingdom, and the United States. We therefore supplemented it with data for other countries from the OECD Employment Outlook (1999, Table 2.2), documenting the changes in severance pay for no-fault individual dismissals in the 1990s. In this way it was possible to code the severance payment variable after 1992 for all countries other than Greece and Israel, so that the series is shorter for these countries. The two final regressors contained in Lazear - other than the time trend - are the share of the population aged 25 to 65 years (WRKAGE) and the growth in GDP per capita (GROWTH). The demographic variable was updated using the Labor Market Statistics source mentioned earlier, while updated information on growth was obtained from the International Financial Statistics Yearbook (IMF, 2002).

To set our severance pay measure, SEV, in wider relief, we also obtained separate data on the severance pay due to a 40 -year-old white-collar employee made redundant after 10 years of service. The two indicators were then converted into rankings (in ascending order of generosity/stringency) and are 
reported in columns (1) and (2) of Table I. Column (3) of this table also gives the country ranking order derived from Heckman and Pagé's (2000) cardinal measure of firing costs (which seeks to control for the entire tenure-severance pay profile), while in columns (4) through (8) we introduce some other widelyused reputation indices, including the employment protection index used by Nickell (1997). Finally, columns (9) and (10) of the table present the corresponding country rankings on the basis of the protection afforded workers by industrial relations and social security laws, respectively.

As indicated by the Spearman ranking correlation at the foot of the table, the three measures of severance pay in columns (1) to (3) are, as expected, highly correlated but the correlation of severance pay with the broad employment protection indicators in columns (4) through (8) displays a less consistent pattern. And the correlations between severance pay and the indicators of industrial relations and social security are extremely low. For their part, the broader indicators of the stringency of employment protection laws are strongly correlated: the correlation coefficients between the column (6) measure - OECD, late 1990s - and columns (4), (5), (7), and (8) are all statistically significant at the 0.01 level. There is seemingly no correlation between the OECD measure and the index of social security reported by Botero et al. (2004) in column (10).

Finally, six labor market institutions are identified in the present treatment. These are the unemployment insurance replacement rate (UIRR); the maximum duration of unemployment benefits (MDUB); expenditure on active labor market policy as a percentage of GDP per member of the labor force (ALMP); union density (UDEN); collective bargaining coverage (UCOV); overall employee and employer coordination in wage bargaining (TCOOR); and the tax wedge (TXWEDGE). As mentioned above, since none of these series is available on a yearly basis, we constructed 5-year averages, 1970-1999, using the interpolations described in Appendix Table AI. ${ }^{7}$ Data sources and variable definitions are also included in this table, as well as Nickell's (1997) time-invariant employment protection index (EPL). Selected descriptive statistics are given in Appendix Table AII.

\section{Findings}

As noted earlier, Lazear's pioneering study acted as the catalyst for more intensive and systematic study of the effects of job security provisions on labor market performance. Almost 15 years after its publication, the Lazear argument that severance pay reduces employment and elevates joblessness (in imperfectly competitive markets) not only remains a mainstay of orthodoxy but also continues to attract broad empirical support (see the survey by Addison and Teixeira, 2003). In what follows while we do not claim to detect any evidence favoring pro-employment effects of stringent labor regulation, 
Table II. Pooled estimations - No country dummies (1956-1999)

\begin{tabular}{|c|c|c|c|c|}
\hline \multirow{2}{*}{$\begin{array}{l}\text { Independent } \\
\text { variable }\end{array}$} & \multicolumn{4}{|c|}{ Dependent variable } \\
\hline & EMPPOP & UNRATE & LTUNRATE & LFPR \\
\hline \multirow[t]{2}{*}{ Intercept } & -0.1305 & 0.1129 & -0.1372 & -0.1080 \\
\hline & $(0.0393)$ & $(0.0276)$ & $(0.3414)$ & $(0.0349)$ \\
\hline \multirow[t]{2}{*}{ SEV } & -0.0064 & 0.0032 & 0.0243 & -0.0055 \\
\hline & $(0.0007)$ & $(0.0005)$ & $(0.0045)$ & $(0.0007)$ \\
\hline \multirow[t]{2}{*}{ GROWTH } & -0.1200 & -0.0024 & 1.5883 & -0.1320 \\
\hline & $(0.0718)$ & $(0.0504)$ & $(0.4882)$ & $(0.0638)$ \\
\hline \multirow[t]{2}{*}{ GROWTH.SEV } & 0.0097 & -0.0005 & 0.0445 & 0.0118 \\
\hline & $(0.0180)$ & $(0.0126)$ & $(0.1471)$ & $(0.0160)$ \\
\hline \multirow[t]{2}{*}{ WRKAGE } & 0.8703 & -0.1582 & -1.2188 & 0.8438 \\
\hline & $(0.0614)$ & $(0.0431)$ & $(0.3117)$ & $(0.0546)$ \\
\hline$F(k, N-(k+1))$ & 72.5 & 83.9 & 23.7 & 108.1 \\
\hline$R^{2}$ & 0.35 & 0.38 & 0.29 & 0.44 \\
\hline$N$ & 833 & 832 & 348 & 833 \\
\hline
\end{tabular}

The regression includes YEAR and YEAR $^{2}$ terms. The LTUNRATE series only begins in 1979. N denotes the number of countries multiplied by the number of observations per country. Standard errors are given in parentheses.

we will nonetheless contend that the more flamboyant empirical findings in the spirit of Lazear need to be interpreted with caution.

To begin with, we take Lazear's parsimonious model and re-estimate it using an additional 15 years of data. Next, in recognition that much data on labor market institutions has only become available in recent years, we test the robustness of the original model to the inclusion of an extended set of such explanatory variables, and in the process address some more contemporary issues. To repeat, in this stage of our empirical analysis we shall look at the effects of severance pay on unemployment and employment for a longer sample period than does Lazear (as previously noted, the exception is the longterm unemployment outcome measure that we substitute for Lazear's working time indicator and for which we have a much attenuated run of data), and in a framework that accommodates time-varying labor market institutions.

Table II shows the results of applying the most restrictive version of the Lazear model, namely, estimation of the effects of severance pay (inter al.) on labor market outcomes using pooled cross-section time-series data with no country dummies. As in Addison et al. (2000, Table 2), the results of this specification are broadly supportive of Lazear's empirical proposition that job protection, proxied by the SEV variable, adversely impacts employment, labor force participation, and overall unemployment. (Also consistent with Lazear is the statistical insignificance of the GROWTH.SEV interaction and the well-determined effects of the population control WRKAGE.) For a shorter time-series, it also appears that the association between SEV and 
Table III. Fixed effects regressions (1956-1999)

\begin{tabular}{lcccc}
\hline \multirow{2}{*}{ Independent variable } & \multicolumn{4}{l}{ Dependent variable } \\
\cline { 2 - 5 } & EMPPOP & UNRATE & LTUNRATE & LFPR \\
\hline SEV & 0.0005 & 0.0017 & 0.0084 & 0.0011 \\
GROWTH & $(0.0005)$ & $(0.0005)$ & $(0.0071)$ & $(0.0005)$ \\
& 0.0089 & -0.0668 & 1.5776 & -0.0237 \\
GROWTH.SEV & $(0.0368)$ & $(0.0360)$ & $(0.2114)$ & $(0.0327)$ \\
WRKAGE & -0.0008 & 0.0064 & 0.0444 & 0.0033 \\
& $(0.0088)$ & $(0.0086)$ & $(0.0630)$ & $(0.0078)$ \\
$F(k, N-(k+1))$ & 0.5724 & 0.0875 & -0.2573 & 0.6356 \\
$R^{2}$ & $(0.0422)$ & $(0.0412)$ & $(0.2180)$ & $(0.0374)$ \\
$N$ & 67.3 & 121.1 & 44.0 & 199.9 \\
& 0.83 & 0.65 & 0.23 & 0.83 \\
\hline
\end{tabular}

The regression includes a constant plus YEAR and YEAR ${ }^{2}$ terms. The LTUNRATE series only begins in 1979. The null hypothesis that the country fixed effects are jointly equal to zero is rejected in all cases. Standard errors are given in parentheses.

long-term unemployment, LTUNRATE, is both negative and well determined (column 3).

Since there no obvious reason to neglect national idiosyncrasies, Table III shows the effect of introducing country fixed effects. Robustness is clearly an issue. The introduction of country dummies renders the coefficient estimates of SEV statistically insignificant in both the EMPPOP and LTUNRATE regressions. The association between SEV and UNRATE remains positive and well determined while there is a sign reversal in the case of LFPR. The absence of country fixed effects is statistically rejected in all regressions at the 0.01 level.

We also tested for the presence of autocorrelation. Table IV gives the results of fitting the fixed effects model assuming a first-order autocorrelation term. It can be seen that the null of no serial (first-order) correlation is clearly rejected. As it is apparent, the re-estimation takes no prisoners: none of the coefficient estimates for SEV is any longer statistically significant at conventional levels.

At this point we are of course reminded of the parsimonious nature of the Lazear model. This is next issue to be tackled. But thus far at least we would conclude that the Lazear model has failed to pass muster. This conclusion is also reached by Addison et al. (2000). The difference here is that we are updating the database with information for more recent years that, with the uptick of unemployment, might perhaps have been expected to offer a more promising milieu for the model.

The parsimony of Lazear's specification has been addressed in various ways in the subsequent literature. But one amendment has proved 
Table IV. Fixed effects regressions with correction for autocorrelation (1956-1999)

\begin{tabular}{lcccc}
\hline \multirow{2}{*}{$\begin{array}{l}\text { Independent } \\
\text { variable }\end{array}$} & \multicolumn{4}{l}{ Dependent variable } \\
\cline { 2 - 5 } & EMPPOP & UNRATE & LTUNRATE & LFPR \\
\hline SEV & -0.00052 & 0.00085 & 0.0043 & -0.00022 \\
GROWTH & $(0.00046)$ & $(0.00054)$ & $(0.0073)$ & $(0.00040)$ \\
& -0.00039 & -0.02576 & 0.9240 & -0.01235 \\
GROWTH.SEV & $(0.01220)$ & $(0.01461)$ & $(0.1391)$ & $(0.01064)$ \\
& 0.00318 & 0.00295 & 0.1003 & 0.00498 \\
WRKAGE & $(0.00268)$ & $(0.00320)$ & $(0.0432)$ & $(0.00233)$ \\
& 0.25701 & 0.03743 & -0.0018 & 0.30429 \\
$F(k, N-(k+1))$ & $(0.05260)$ & $(0.06009)$ & $(0.2720)$ & $(0.04604)$ \\
$N$ & 10.7 & 10.1 & 13.4 & 20.5 \\
\hline
\end{tabular}

The regression includes a constant plus YEAR and YEAR ${ }^{2}$ terms. The LTUNRATE series only begins in 1979 . The null hypothesis that the country fixed effects are jointly equal to zero is rejected in all cases. The null hypothesis that the error term is not first-order autoregressive is also rejected. Standard errors are given in parentheses.

increasingly popular, namely, the class of models whose general specification is described in Equation (2) above. Their distinctive feature is the introduction of time-varying measures of labor market institutions, on the one hand, and time dummies as proxies for unobservable shocks, on the other. One of the first authors to apply this specification was Nickell (1997), who combined two-time periods - 6-year averages of data for 1983-1988 and 1989-1994 with a wide set of explanatory variables.

We begin with a quasi-replication of Nickell's (1997) approach in Table V. In this exercise the left hand side variables are again extracted from our own database, whereas the right hand side variables are taken from Nickell. The surprising result is the statistical insignificance of most of the parameter estimates. But there is some support for Lazear's findings: the higher the EPL ranking (i.e. the more generous employment protection), the lower the employment population ratio and labor force participation. Moreover, the long-term unemployment rate - but not overall unemployment - is also impacted unfavorably by employment protection legislation. Appendix Table AIII reports a somewhat different exercise in which both the right hand side and left hand side variables are taken from our own database, with the exception of ALMP and benefit duration. There is obvious corroboration of the findings in Table V. Taken together, these results suggest that quasicross-section data (two data points spanning two decades) if they do not make a strong case for labor market institutions do offer a measure of support for Lazear.

Tables VI and VII show the more interesting case in which the number of data points has been enlarged. But this extension is not achieved without 


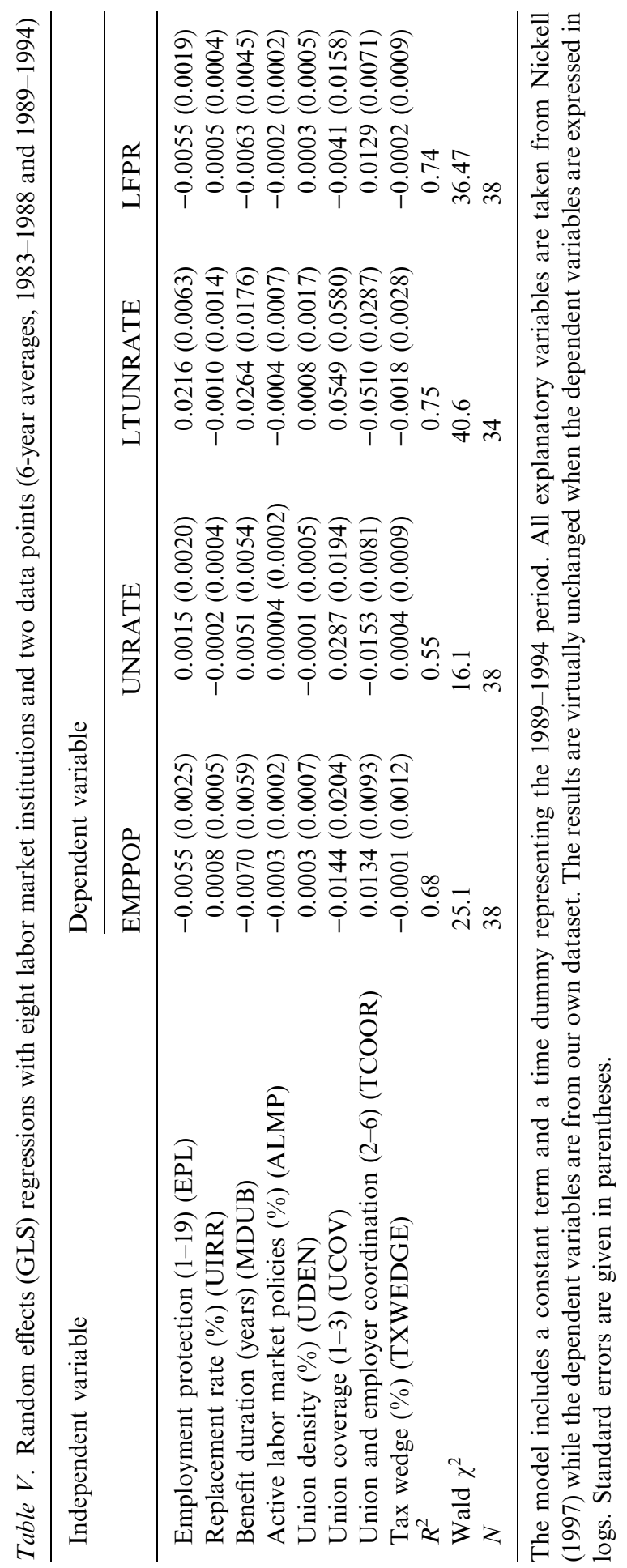




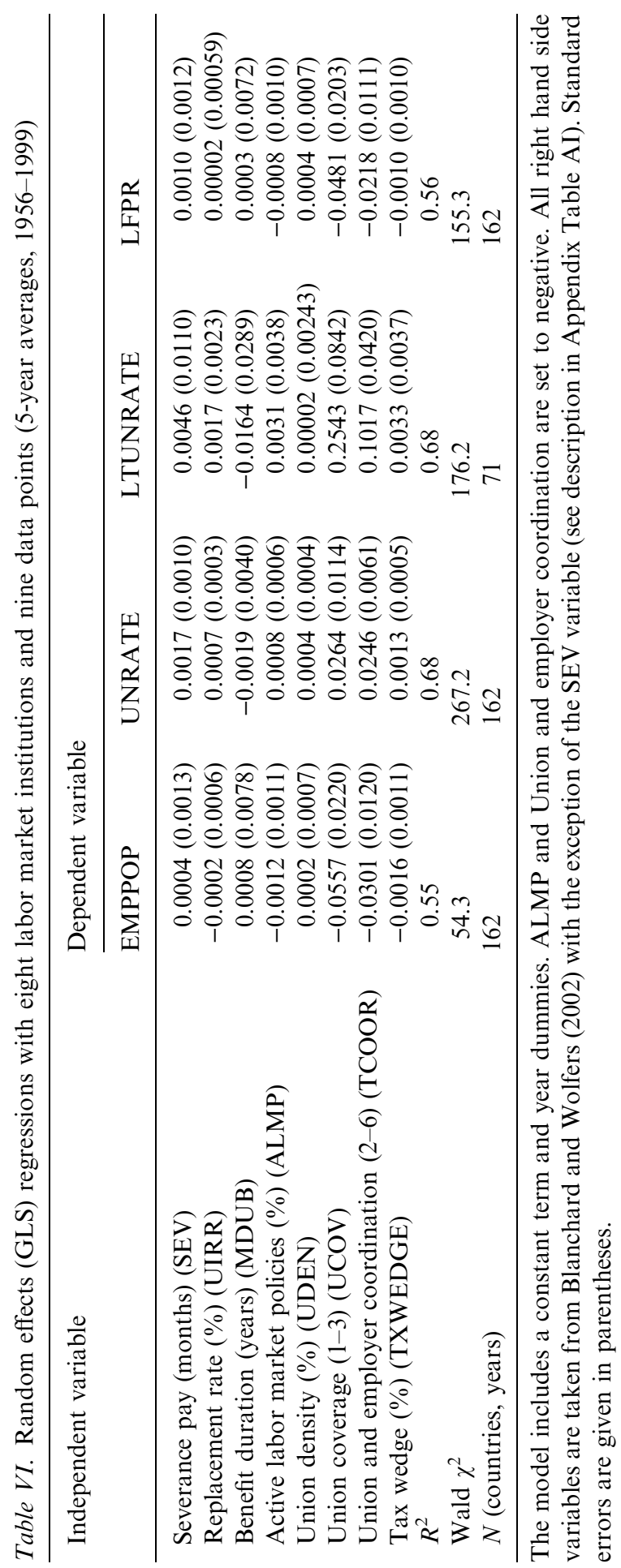




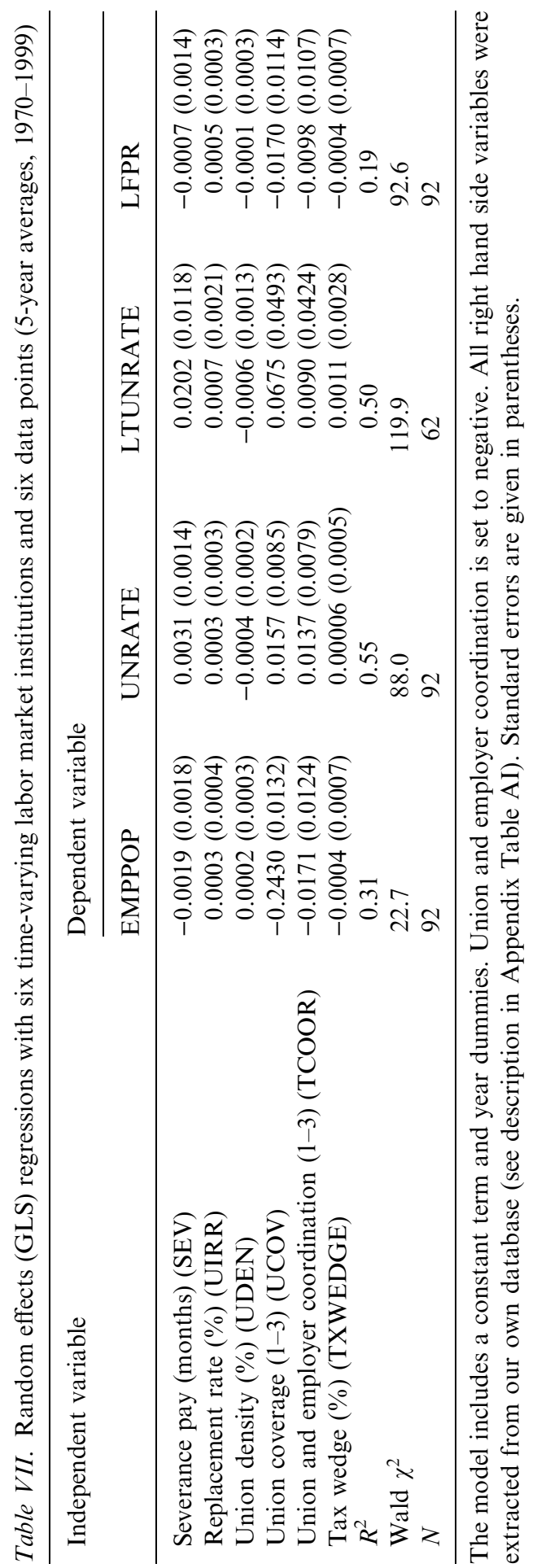


cost. Thus, in Table VI, we have a maximum of nine intervals covering the entire sample period 1956-1999 and seven fixed labor market institutional variables (the replacement rate, benefit duration, ALMP, union density, union coverage, union and employer coordination, and the tax wedge) plus the severance pay variable. In Table VII the sample period is 1970-1999, but we have a smaller number of labor market institutions which are now time varying. The Nickell study considered eight institutional variables of which one is time-invariant (EPL).

Clearly, these innovations produce an improvement in the precision of the institutional variables in the case of UNRATE (in both tables). For the other regressions (EMPPOP, LTUNRATE, and LFPR), the coefficient estimates are statistically significant in just 6 out of 24 cases in Table VI and in only 3 out 18 cases in Table VII. But the SEV coefficient is now well determined only in 3 out of 8 regressions (taking Tables VI and VII together), whereas in Table V and the Appendix Table AIII it was well determined in 6 out of 8 cases.

We also report in Table VIII the results from a different exercise using annual data (1956-1999) in which we have added seven fixed institutional variables (including the tax wedge) to the full set of original Lazear regressors. ${ }^{8}$ It can be seen that 14 out of the 32 (i.e. $8 \times 4$ ) coefficient estimates are now statistically significant, which is a slight improvement over Table VI, for example, where 11 coefficients were well determined. In particular, the SEV variable is positively signed and statistically significant in the UNRATE and LTUNRATE equations (albeit only at the 0.10 level in the latter). Bearing in mind the results from Table IV above, it can be seen that the SEV coefficient estimate does show some sensitivity to the inclusion of labor market institutions. Based on the same type of augmented-Lazear specification, we then sought to determine the degree of sensitivity of the severance pay coefficient in Table IV to the introduction of all possible combinations of institutional variables (viz. the seven fixed measures mentioned above). From this exercise it emerged that the SEV coefficient estimate was never statistically significant in the EMPPOP regression, but was always positive and well determined in the in the UNRATE regression. The 'addition' of the institutional covariates to the LTUNRATE regression yielded a marginally statistically significant coefficient estimate for SEV in roughly 50 percent of the cases, while in the LFPR equation the estimate was statistically significant (although on this occasion at both the 0.05 and 0.10 levels) in approximately two-thirds of all cases. In sum, while the sensitivity of the SEV coefficient in the EMPPOP equation seems to be low, in the other three cases - UNRATE, LFPR and LTUNRATE - sensitivity to model specification cannot be ignored. Nonetheless, the consequences for standard Lazear equations of ignoring labor market institutions are arguably less severe than might be expected, although a more definite conclusion necessarily awaits the provision of better (i.e. annual) data on institutions. 


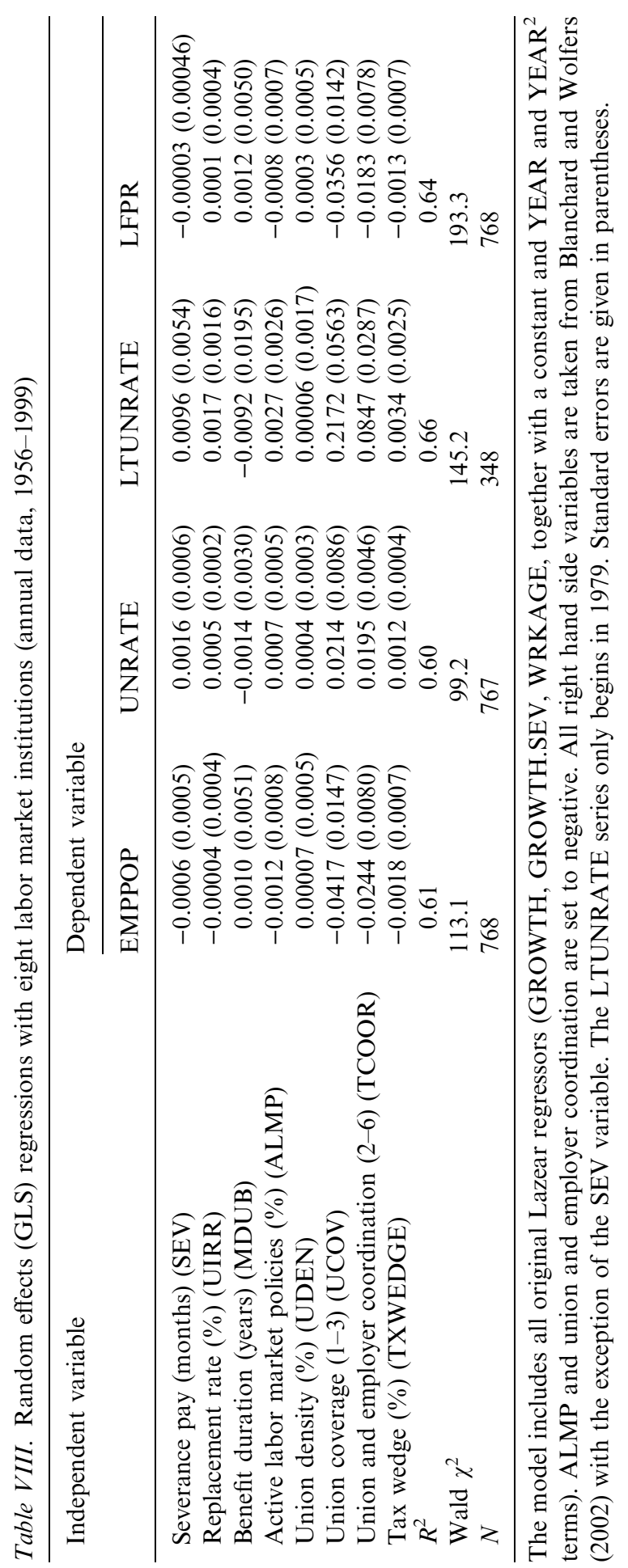


We should also note that we experimented with alternative measures of employment protection legislation in substitution for SEV and Nickell's (1997) EPL index. But the broad picture is unchanged: the role of institutions is less 'active' than one might expect. Our finding that institutions seem to be of greater importance in explaining overall unemployment than the other indicators is also worthy of note. To some degree, it parts company with the notion that the impact of labor regulations on unemployment is more ambiguous than its effects on employment.

These remarks bring us finally to model (3). In this model, it is hypothesized that labor institutions only reveal their true 'color' in conjunction with adverse economic conditions (e.g. negative shocks). Accordingly, if a given country is 'endowed' with a non-employment friendly set of labor laws, the unfavorable impact of the latter may not surface if that nation manages to avoid hard times. The non-linear specification of Equation (3) is particularly suited to address the interaction between (observed or unobserved) shocks and institutions.

In fitting this model to the data we again consider the sample period 19701999 and the same 5-year averages as before. The set of time-varying institutions is also the same; in particular, we retain the SEV variable as our indicator of employment protection. In other words, we are implementing here the 'work-in-progress' component of Blanchard and Wolfers' (2002, p. C23) analysis, that is to say, a model in which all institutional regressors are allowed to vary over time. We note that Blanchard and Wolfers attempted to run the model with time-varying institutions, but only in a limited way, using just the employment protection and unemployment insurance covariates. Blanchard and Wolfers also focus exclusively on the course of unemployment, and so do not consider the LTUNRATE, LFPR, and EMPPOP outcome indicators considered here. (We note that Bertola et al., 2001, likewise concentrate on unemployment developments.) Finally, observe that although data on observable shocks is available we restrict our attention to the case of unobservable shocks proxied by time dummies.

The results of this analysis are presented in Table IX. In only 7 out of 24 cases are the labor market institutional parameters estimated with precision. The SEV variable is statistically significant in just the UNRATE equation, while UCOV and TCOOR are never statistically significant. Most surprisingly, developments in long-term unemployment are almost solely explained by country and time effects, with no role reserved for labor market institutions. We note parenthetically that the restricted version of model (3) - that is, the model in which $X_{i j}$ is time invariant - fully replicates Blanchard and Wolfers findings for unemployment (e.g. their Table 1), with all variables being identically signed and statistically significant (the active labor market policy and union density covariates are not statistically significant). Applying 


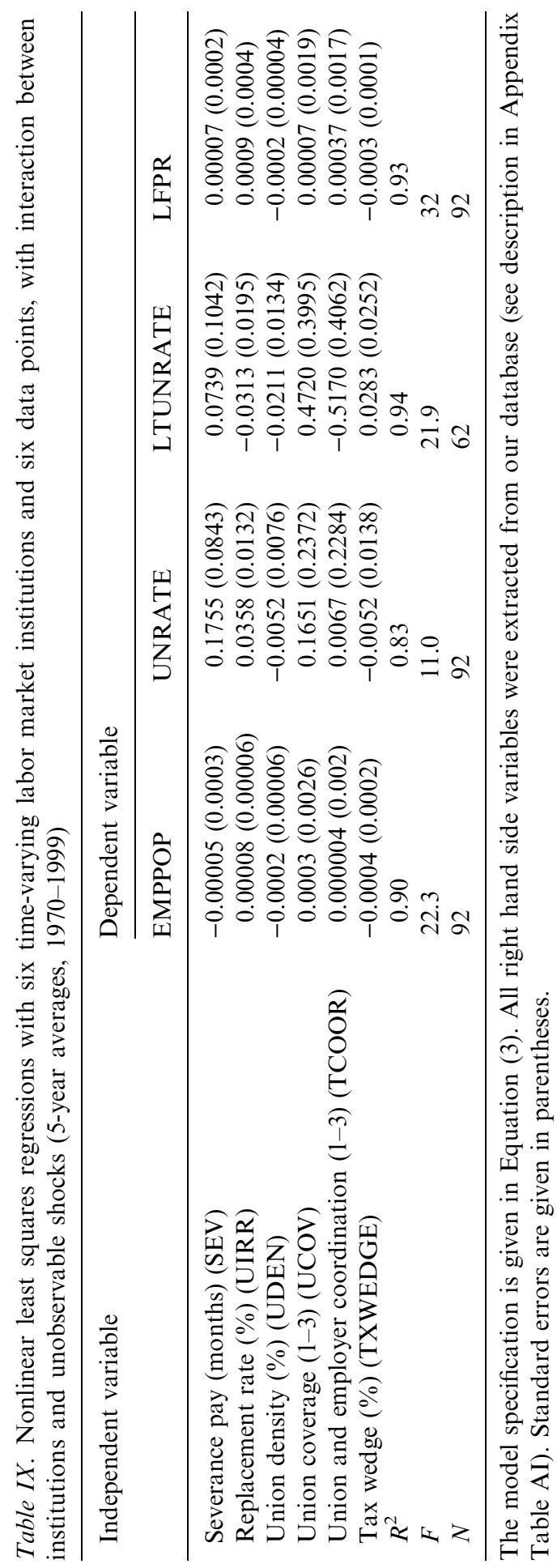


the same model to the EMPPOP, LFPR, and LTUNRATE outcomes revealed approximately the same pattern as described in Table IX. In the case of the long-term unemployment regression, none of the coefficient estimates was statistically significant. What these results show is the seemingly inability of labor market institutions as a whole to materially impact labor market outcomes under the more realistic scenario of time-varying indicators. The SEV variable, with the exception of the unemployment case, does not seem to play any particularly prominent role either. The attenuated role of collective bargaining coordination is further weakened.

\section{Conclusions}

The directional effects of job security provisions on job turnover (i.e. job creation and job destruction) and on unemployment flows are fairly well established. Net effects are less firmly established, despite widespread acceptance of the view that stronger employment protection will entail lower employment and higher unemployment. In the present treatment, we have offered a wide-ranging combination of empirical strategies in which the effects of institutions on labor market aggregates are analyzed across a variety of sample periods, explanatory variables, and estimation techniques.

Our starting point was the influential Lazear study of the role of severance pay in influencing employment and joblessness. By adding more regressors specifically, labor market institutions - to the original Lazear model, we found little slippage of the unemployment result. Much weaker, however, was the evidence linking severance pay to the rate of long-term unemployment, to the employment-population ratio, and to the labor force participation rate. Surprisingly, in virtually all model specifications and irrespective of the empirical strategy used, we found low statistical significance of the other institutional variables. Even the performance of the union and employer coordination variables, often viewed as favorable to labor market development, was not impressive overall.

We cannot of course conclude from the foregoing exercise that labor market institutions - and job protection in particular - do not matter. Rather, our findings indicate that we simply do not yet know enough about the role of such institutions, or, expressed differently, that the extent of their adverse impact on the labor market is not easily gauged. For instance, we cannot exclude the possibility that different combinations of labor institutions and regulations may produce quite similar outcomes. It may even be the case that the quest for improved labor market performance is better directed elsewhere, although we would resist this interpretation, arguing that lingering uncertainty as to the impact of the institutions identified here is an inescapable consequence of the vintage of research in this area. 


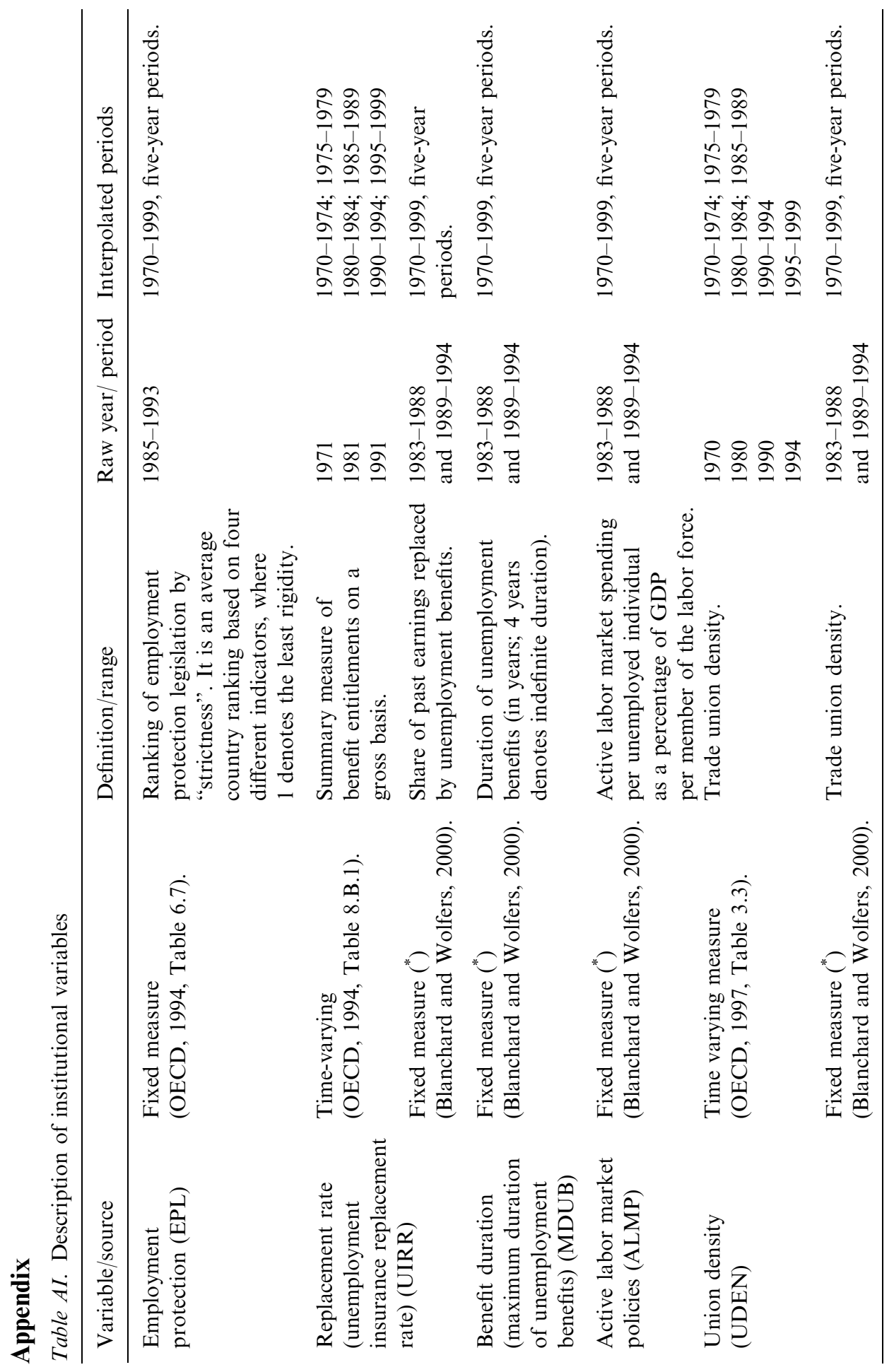




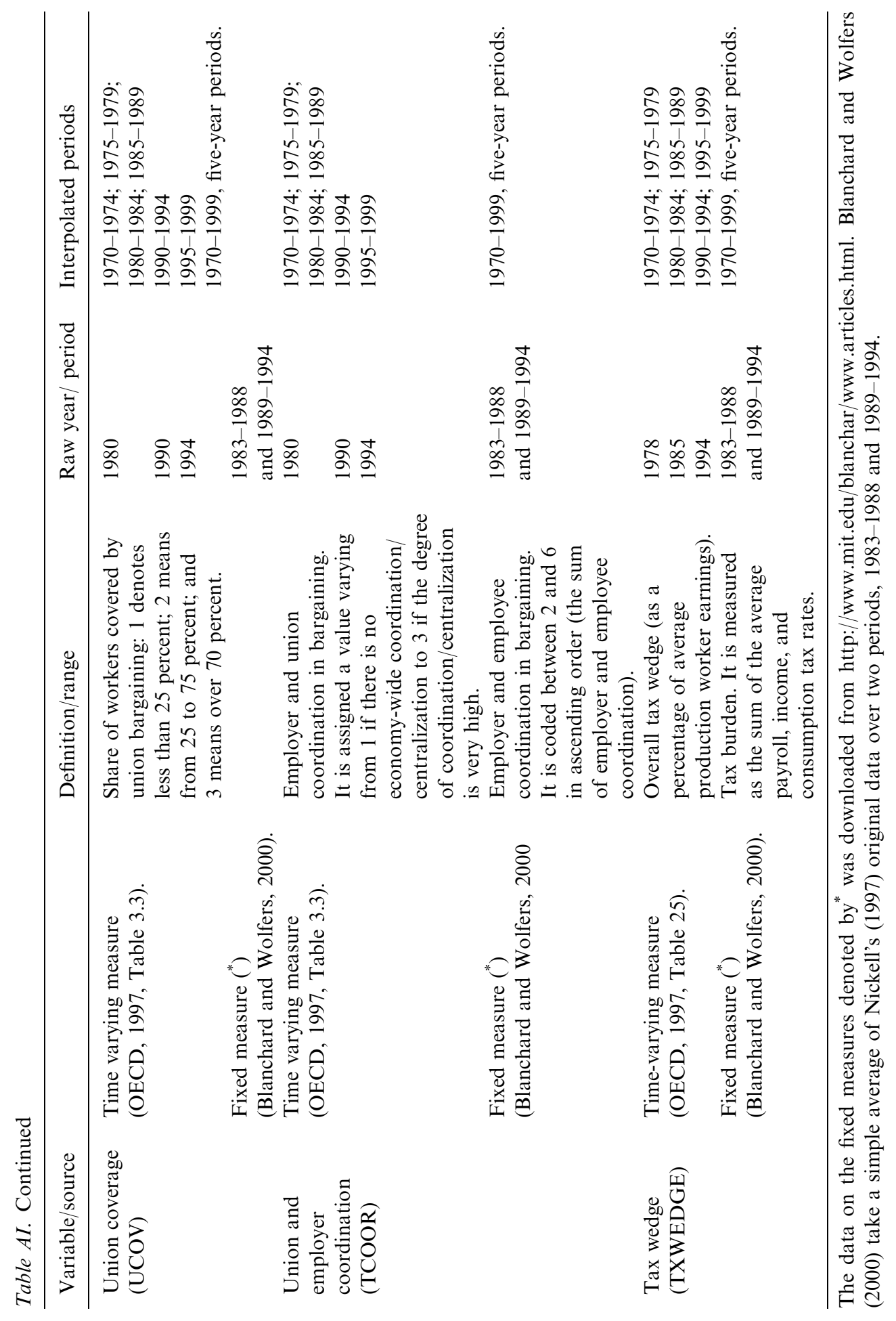




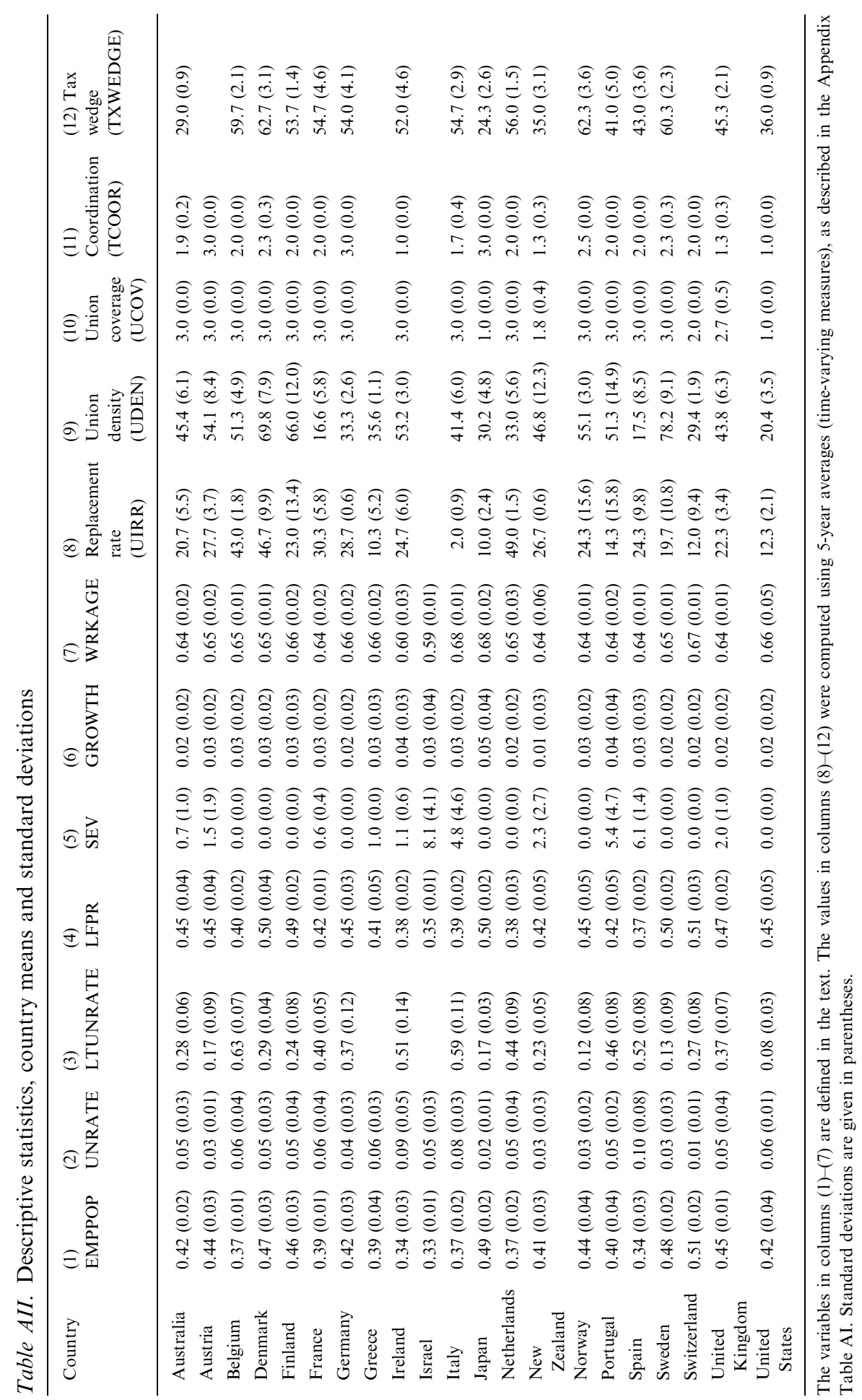




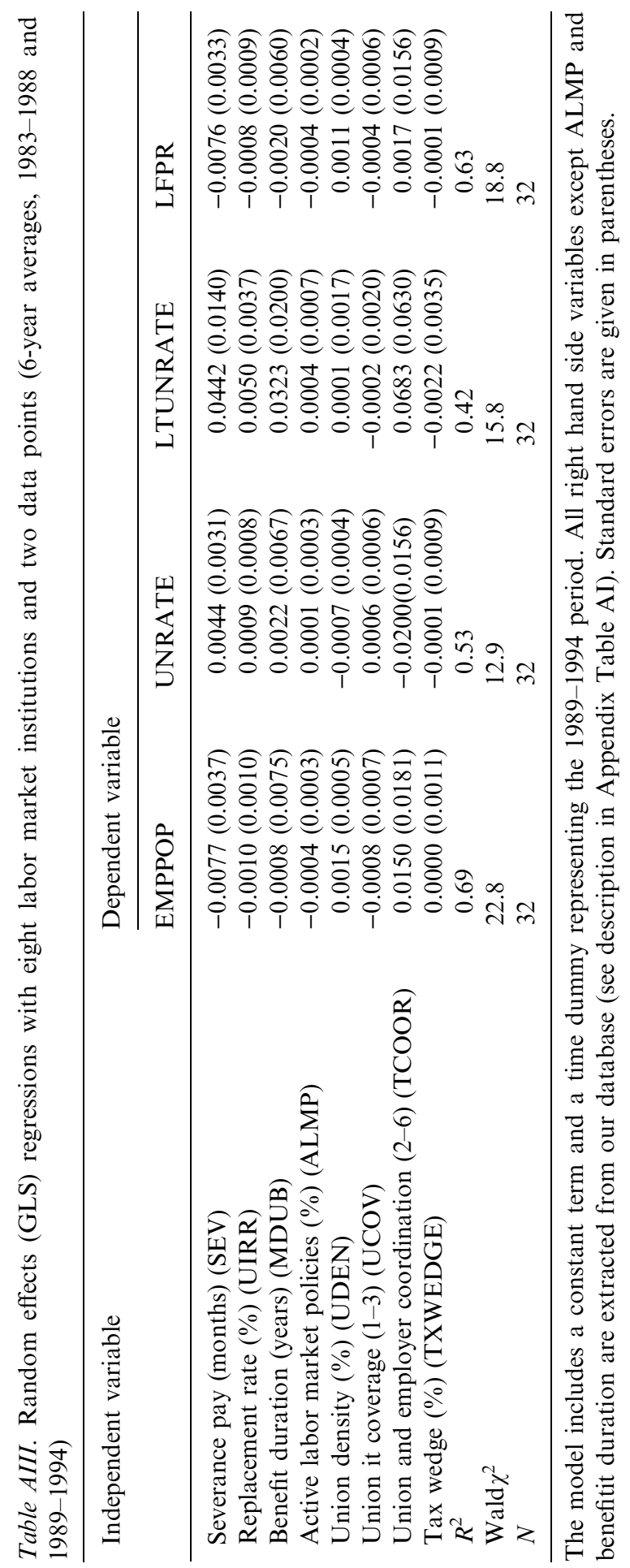




\section{Notes}

1. For the flavor of the earlier literature, see Buechtemann (1993).

2. Lazear rationalized his finding that average hours were reduced in more generous employment protection regimes on the grounds that employers might be expected to substitute unprotected part-time for full-time workers. Yet, as practical matters, not only do part timers tend to enjoy the same (strictly proportional) employment protection as full timers but also we were unable to replicate Lazear's hours results (see Addison et al., 2000). Accordingly, we chose to substitute for the hours indicator another outcome measure often used in the literature, namely, long-term unemployment.

3. This raises the specter of research Darwinism, alluded to by Blanchard and Wolfers (2000, p. C22).

4. Restricting the sample to long-standing OECD nations assures a rectangular data set with reasonably comparable measures across countries, but a bigger sample might provide richer insights into the labor market effects of severance pay. In Latin America countries, for example, severance pay has historically been the primary mechanism for providing income security between jobs, whereas nations in our sample have more extensive systems of support. (For information on income security provisions in Latin America, see Jaramillo and Saavedra, 2003; Ferrer and Riddell, 2003.) Accordingly, severance pay might have more statistical leverage in Latin-American nations. Heckman and Pagés (2000) confirm that the level of severance pay, measured in multiples of monthly wages, is considerably higher in these countries than in the more industrialized OECD nations, and duly report some very strongly negative employment effects of their severance pay measure in Latin America. That said, they also find that unemployment effects are actually stronger for more developed nations.

5. Addison et al. (2000) discuss the problems arising from a panel specification such as Equation (1).

6. In this case, the difference between the coefficient estimate for the first time dummy and the last time dummy gives the change in $y_{i t}$ due to exogenous shocks (if $X_{i t}=\bar{X}$, then $\left.\hat{y}_{i t}=\hat{c}_{i}+\hat{d}_{t}\right)$. We do not discuss the case of observable shocks.

7. Lack of data on these labor market institutions for Greece and Israel reduces our sample to 19 countries once we proceed beyond Lazear's parsimonious specification.

8. This exercise was carried out using the GLS random effects model to accommodate time-invariant regressors. The seven fixed regressors used in the model correspond to Blanchard and Wolfers (2000) 'fixed institutions' case, where the (fixed) value for each institution was obtained by averaging the corresponding values computed by Nickell (1997) for the periods 1983-1988 and 1989-1994.

\section{References}

J.T. Addison and P. Teixeira (2003) 'The Economics of Employment Protection', Journal of Labor Research 25, 85-129.

J.T. Addison, P. Teixeira and J.-L Grosso (2000) 'The Effect of Dismissals Protection on Employment: More on a Vexed Theme', Southern Economic Journal 67, 105-122.

G. Bertola, T. Boeri and S. Cazes (1999) Employment Protection and Labour Market Adjustment in some OECD Countries: Evolving Institutions and Variable Enforcement, Employment and Training Papers 48. Geneva: International Labor Office.

G. Bertola, F. Blau and L.M. Kahn (2001) Comparative Analysis of Labor Market Outcomes: Lessons from International Long-Run Evidence, in Krueger, and Solow, eds., The Roaring Nineties: Can Full Employment Be Sustainable?. New York, NY: Century and Russell Sage Foundations. 
O. Blanchard and J. Wolfers (2000) 'The Role of Shocks and Institutions in the Rise of European Unemployment: The Aggregate Evidence', Economic Journal 110, C1-C33.

J. Botero, S. Djankov, R. La Porta, F. Lopez-de-Silanes and A. Shleifer (2004) 'The Regulation of Labor', Quarterly Journal of Economics 119, 1339-1382.

C.F. Buechtemann (1993) Introduction: Employment Security and Labor Markets, in Buechtemann, ed., Employment Security and Labor Market Behavior - Interdiscliplinary Approaches and International Evidence. Ithaca, NY: ILR Press.

R. Di Tella and R. MacCulloch (1999) 'The Consequences of Labor Market Flexibility: Panel Evidence Based on Survey Data', Unpublished paper, Harvard Business School, April.

A. Ferrer and W.C. Riddell (2003) 'Unemployment Insurance Savings Accounts in Latin America: Overview and Assessment', paper presented at the International Workshop on Severance Pay Reform: Toward Unemployment Savings and Retirement Accounts, Laxenberg/Vienna, November.

J.J. Heckman and C. Pagés (2000) The Cost of Job Security Regulation: Evidence from Latin American Countries, NBER Working Paper 7773. Cambridge, MA: National Bureau of Economic Research.

IMF, (2002) International Financial Statistics Yearbook. Washington, D.C.: International Monetary Fund.

M. Jaramillo and J. Saavedra (2003) 'Severance Payment Programs in Latin America', paper presented at the International Workshop on Severance Pay Reform: Toward Unemployment Savings and Retirement Accounts, Laxenberg/Vienna, November.

E.P. Lazear (1990) 'Job Security Provisions and Employment', Quarterly Journal of Economics 105, 699-726.

Mercer Human Resource Consulting, (2003) European Employment Conditions, Mimeographed. London: MHRC.

S. Nickell (1997) 'Unemployment and Labor Market Rigidities: Europe versus North America', Journal of Economic Perspectives 11, 55-74.

OECD (1999) 'Employment Protection and Labor Market Performance', Employment Outlook, June, pp. 49-132.

OECD, (1997) The OECD Jobs Strategy, Making Work Pay: Taxation, Benefits, Employment and Unemployment. Paris: Organisation for Economic Co-operation and Development.

OECD (1997) 'Economic Performance and the Structure of Collective Bargaining', Employment Outlook, July, pp. 63-92.

OECD, (1994) The OECD Jobs Study, Evidence and Explanations, Part II: The Adjustment Potential of the Labor Market. Paris: Organisation for Economic Co-operation and Development. 